\title{
How Many Pharmacists Are In Our Future?: The Bureau of Health Professions Projects Supply to 2020
}

\begin{abstract}
OBJECTIVE: To describe a Bureau of Health Professions (BHPr) model for estimating the numbers and selected demographic characteristics of active pharmacists in the United States and to relate the model's findings.
\end{abstract}

DESIGN: We constructed a model using as base counts data from the Pharmacy Manpower Project census of 1989-1991 and advancing the counts annually based on estimates of pharmacists entering and leaving the workforce. The total number of active pharmacists in any year was the sum of the male and female cohorts from age 24 through age 75 . The model and its underlying assumptions included consideration of U.S. graduates through 1998, international pharmacy graduates who become licensed in the United States, new schools, type of entry-level degrees, and separation rates.

RESULTS: The basic series projected 196,011 active pharmacists in 2000 , 224,524 by 2010 , and 249,086 by 2020. Estimated pharmacists per 100,000 population were 71.2 in 2000 ,
74.9 in 2010 , and 76.7 in 2020 . The workforce was projected to consist increasingly of women: $32 \%$ in 1991 , $46 \%$ in $2000,50 \%$ in 2003 , and $64 \%$ in 2020. Percentages of graduates receiving the B.S. degree fell from $94 \%$ (1980) to $64.4 \%$ (1998) and were projected to decrease to $0 \%$ by 2005 . Estimates of total pharmacists in 1998 were similar to those from other sources.

CONCLUSION: The BHPr model, which can be readily revised as more and better data become available, provided estimates of active pharmacists by age and sex from 1991 to 2020 . The model portrayed an increasingly female pharmacy workforce, with more pharmacists holding the Pharm.D. degree. The model and data are useful for research, analysis, and health care planning.

KEYWORDS: Pharmacist supply, health care workforce, workforce modeling

J Managed Care Pharm 2000: 474-82 Service and Safety Evaluator, Office of Biostatistics and Epidemiology, Center for Biologics Evaluation and Research, Food and Diug Administration, Rockville, MD. JAMES M. CULTICE, BS, is Technical Director for Modeling and Research, National Center for Health Workforce and Analysis, Bureau of Health Professions, Health Resources and Services Administration, U.S. Department of Health and

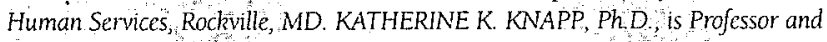
Associate Dean Unversity of the Pacific School of Phamacy and Health Sciences, Stockion, $C A$

AUTHOR CORRESPONDENCE Katherne K Knapp, PhD School of Phamacy and Health Sciences, Untversity of the Paific, 3601 Pacific Avenue, Stockton, CA 95211 Tel, 20929462561, Eax 209-946-3147, E mail knapp@uop.edu. ACKNOWLEDGMENT Presented at the Annual Meeting, American Solety of Healch-System Pharmacists, Philadelphia, PA, June 5, 2000. This article is being simultaneously published in the November/December 2000 issue of the joumal of the American Pharmaceutical Association. The authors thank RADM Fred Paavola, Chief Pharmacy Officer, U.S. Public Health Service, Bureau of Health Professions, Health Resources and Senvices Administration (HRSA), and Stuart Bemstein, Health Statistictan, Bureau of Health Professions, National Center for Health Workforce Information and Analysis, HRSA, for their valued support and assistance on this project

\author{
by Sharon K. Gershon, James M. Cultice, and \\ Katherine K. Knapp
}

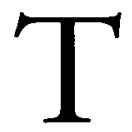
here is growing apprehension and mounting evidenc in the pharmacy community and among health cal policymakers that the future supply of pharmacis may not be adequate to meet the nation's needs for pharm: ceutical services. ${ }^{1.2}$ The sharp increase in vacancies and th inability to fill positions, the rapid growth in prescription vo ume, the increase in new drugs and their greater complexitie and the growth in the elderly population are all indicators of rapid and persistent rise in demand for pharmacists. In add tion, the national focus on medication errors, some attributab to inadequate pharmacist staffing and job stress, have draw attention to the need for an adequate supply of pharmacists.

Concern about this problem in the United States is not ner Studies addressing the demography and work patterns of pha macists have appeared, particularly during periods of shor age..$^{3-10}$ These efforts, and the authors' ability to explain even such as periodic shortages, have been hampered by the scarc ty of basic data about the size and characteristics of the pha macy workforce. Today pharmacists represent the third-large health professional group in the United States, and yet pha macy lags behind other health professions in the area of da collection. For example, the American Medical Association, th American Dental Association, and the American Academy Physician Assistants maintain and update comprehensir national databases that provide detailed demographic and ger graphic information about their professions' compositio: Parallel data do not exist about pharmacists.

In the absence of a current comprehensive database, pha macist workforce studies have relied on surveys based on san ples, census surveys, and modeling. The last national cens1 count of pharmacists was completed in the early 1990s ar does not account for more recent events, such as the openir of new schools, recent enrollment trends, transitioning to th doctor of pharmacy (Pharm.D.) entry-level degree, or the col tinuing rise in the number of women pharmacists. ${ }^{11}$

Over the past two years, the Bureau of Health Profession (BHPr), which has historically created and maintained mode for health care workers, constructed a pharmacist-supp model and applied it to generate new estimates of pharmaci numbers and characteristics in the United States through 202 The model includes a basic series and high and low alternati series based on alternative assumptions about new entran into the workforce. 


\section{Objectives}

The purpose of this article is to describe the BHPr Pharmacist Supply Model and relate its findings. We provide projections of the supply of active pharmacists under different scenarios using the latest available data on enrollment and graduate trends and assumptions about losses from the supply pool. Also presented are estimates of the distribution of the workforce by age and sex in 2000, and the percentage of Pharm.D. graduates. The data generated by the model are expected to provide an authoritative source of baseline and predictive data about pharmacists. The data should be useful to a wide range of individuals and organizations that depend on the availability of pharmacists and pharmaceutical services, including health planners at the federal, state, and local levels; managed care organizations; health researchers; pharmacy educators; professional associations; and employers of pharmacists in community and institutional pharmacies and in the pharmaceutical industry.

\section{Methods}

\section{Structure of the Model}

The BHPr Pharmacist Supply Model is based on a year-by-year progression of cohorts of pharmacists designated by age and sex. The total number of pharmacists in any given year is the sum of men and women from one-year age group cohorts extending from age 24 through age 75 . The model takes base year counts of active pharmacists, extracted from the Pharmacy Manpower Project (PMP) census database." The numbers are then projected forward in time by (1) adding, each year, the projected number of new entrants; and (2) subtracting, each year, the projected number of both base-year pharmacists and post-1991 new entrants who will die or retire. At any point in time the composite of base-year pharmacists and new entrants who have neither died nor retired constitutes the active pharmacist supply. The process is iterated from base year 1991 through 2020, the end of the present forecast period.

The data for the base cohorts were drawn from the 1989-1991 PMP Census Project; we identified 1991 as the base year for the model. The historical data for new graduates were drawn from the American Association of Colleges of Pharmacy (AACP) annual reports on enrollments and graduates. The number of survivors in each sex- and age-based cohort throughout the projection period was estimated by applying a separation rate that computes the percentage of a particular cohort leaving the workforce in the following year.

\section{Estimates of New Graduates and New Schools}

We obtained data on historic graduates by sex and entry-level degree (bachelor of science or doctor of pharmacy) from 1991 through 1998 from AACP. To estimate new graduates from 1999 through 2020, we reviewed three variables that could influence future enrollments.
First, we looked at new schools of pharmacy. Eight new schools were founded between 1980 and 2000, and we anticipated that additional schools would be opened through 2020 .

Second, applications to pharmacy programs have been fluctuating: They increased during the first half of the 1990s and decreased during the second half. Therefore, at a time when the number of places with pharmacy programs was increasing, the number of applicants was decreasing. Insufficient applicants could render the opening of new schools infeasible.

Finally, we considered the transition to the entry-level doctor of pharmacy (Pharm.D.) program. Of the 81 schools of pharmacy, all but 11 made the transition to the Pharm.D. degree during the 1990s. For those schools still in transition, we needed to know whether the conversion would result in changes in graduate numbers. When telephone inquiries were directed to the 15 schools still in transition, 9 schools indicated their intent to at least maintain current enrollments. Planned decreases among the remaining schools ranged from $9 \%-20 \%$.

Based on the information gathered from the inquiries, we assumed that all current schools would continue to exist and that each new school would eventually add 90 graduates per year, the average value for existing schools. For the basic series, we assumed that three schools would be added from 2000 to 2010 and three more schools from 2010 to 2020. We chose this rate, which was slightly lower than the rate of new school openings over the past 20 years, because of the continuing decline of the applicant pool, which could interfere with the feasibility of new schools. For the low series, we assumed that no schools would be added after 2000; for the high series, we assumed that one new school would be added every other year throughout the projection period, a rate higher than the historical average over the past 20 years.

\section{International Pharmacy Graduates}

The supply of most health professionals in the United States is augmented by the addition of graduates from other countries who become licensed to practice in the United States. Historically, international pharmacy graduates (IPGs) have not entered practice in the United States in large numbers. For example, an earlier report estimated that approximately 200 IPGs per year were licensed to practice pharmacy in the mid1980s. ${ }^{12}$ Nevertheless, we felt it was appropriate to include a variable for IPGs in the model, and we investigated the status of IPGs in the workforce.

We contacted the National Association of Boards of Pharmacy (NABP) to obtain data on the number of IPGs who had passed the North American Pharmacist Licensing Examination (NAPLEX) since 1990; these data indicated that during 1997, 1998, and 1999, there were 163, 266, and 358 IPGs licensed, respectively. Opposing this upward trend, NABP has declared that in 2003, when the requirement for an entry-level Pharm.D. degree begins to be enforced nationally, IPGs will be eligible to take the 
NAPLEX only if they hold a five-year pharmacy degree. Because most pharmacy programs outside the United States are fouryear programs, this change in NABP policy is likely to reduce IPG entrants into U.S. practice, although some pharmacy schools may find it attractive to develop programs addressing this deficit.

Because California has its own licensing process, we contacted the California State Board of Pharmacy for similar information. Its data showed that during 1997, 1998, and 1999, there were 52, 56, and 51 IPGs licensed, respectively. Additionally, data on California pass rates showed that IPGs had consistently low pass rates, suggesting that many IPGs took the examination more than once before passing. In 1998 the California State Board of Pharmacy voted to require any candidate who had failed the examination four times or more to complete a substantial amount of graded coursework in the regular pharmacy curriculum at an accredited school of pharmacy before attempting the examination again. The opportunities for enrollment in coursework meeting the Board's requirements have been very limited, and thus we assumed that future numbers of IPG pharmacists entering practice in California would remain at current levels. Again, the possibility exists that schools could decide to offer programs meeting the California Board's requirements.

Based on these limited data, we estimated an annual addition of 314 IPGs to the pharmacy workforce due to IPGs for the basic series of the revised model. This number represents the mean of total IPGs (NAPLEX plus California) each year from 1997 through 1999. For the low and high series, we subtracted or added 97 IPGs, which represents the value of one standard deviation from the mean of 314. Thus, for the low series, we used a constant value of 217 IPGs each year, and for the high series, 411 IPGs each year.

\section{Separation Rates}

Separation rate tables are an essential tool for modeling departures from the workforce over time. The rates, which are usually based on actuarial estimates of retirement, death, and sometimes occupational mobility (changing one's type of job), describe the percentage of an age- and sex-based cohort that will leave the workforce in a given time period. As an example, a one-year separation rate of 0.005 for a cohort of 30-year-old women pharmacists would be used to calculate that $99.5 \%$ of this cohort would remain in the workforce as 31-year-olds.

Compiling reliable separation rates for the range of working years (generally the early 20 s to over 75 years of age) requires large amounts of data, leading to a scarcity of rate tables specific to a given occupation or a given point in time. Lacking a separation rate table specific to pharmacists, an earlier study applied rate tables for physicians and clerical workers to a model of pharmacists divided into age- and sex-based cohorts, resulting in vastly different supply estimates over time. ${ }^{13}$ Since a rate table

\begin{tabular}{l|c|c}
\hline TABLE 1 & $\begin{array}{l}\text { Bureau of Labor Statistics Civilian } \\
\text { Separation Rates by Age and Sex, } \\
\text { 1988 }\end{array}$ & Male \\
\hline Age & 0.002 & 0.005 \\
\hline $24-29$ & 0.002 & 0.001 \\
\hline $30-34$ & 0.004 & 0.001 \\
\hline $35-39$ & 0.006 & 0.011 \\
\hline $40-44$ & 0.015 & 0.024 \\
\hline $45-49$ & 0.029 & 0.040 \\
\hline $50-54$ & 0.075 & 0.080 \\
\hline $55-59$ & 0.124 & 0.120 \\
\hline $60-64$ & 0.110 & 0.119 \\
\hline $65-69$ & 0.144 & 0.160 \\
\hline $70-74$ & 0.200 & 0.200 \\
\hline 75 and over & & \\
\hline
\end{tabular}

specific to pharmacists still does not exist, we reviewed the available rate tables and tested several sets of rates to see which set was the best predictor. The test involved systematically applying different rate sets to project the 1978 base count of active pharmacists to 1991 and comparing the results with the base counts of the PMP census. ${ }^{11}$ This test showed the extent to which different separation rate tables matched the workforce participation behavior of pharmacists during the 1980s. Based on this analysis, we chose to use the 1988 civilian labor force separation rates from the Bureau of Labor Statistics (BLS). This data set consisted of separation rates by sex for five-year agebased cohorts (see Table 1, above). Applying these rates and the differing assumptions about graduate entrants, we developed a low series, a basic series, and a high series that estimates pharmacy graduates and pharmacist numbers by sex and age from 1991 through 2020.

\section{Results}

Table 2, opposite, describes the pharmacist estimates derived from the BHPr "Pharmacist Supply Model. All estimates described here are drawn from the basic series unless otherwise specified. The model projects 196,011 active pharmacists for 2000. The supply of active pharmacists is projected to reach 224,524 by 2010 and 249,086 by 2020 , a $45 \%$ increase over the 1991 PMP census estimate of 171,611, an annual growth rate of $1.3 \%$. In the alternative estimates, total supply is projected to range from 221,823 (low series) to 226,791 (high series) in 2010 , a difference of $2.2 \%$. By 2020 , the alternative projections range from 242,034 (low series) to 253,919 (high series), a difference of $4.7 \%$. 
How Many Pharmacists Are in Our Future?: The Bureau of Health Professions Projects Supply to 2020

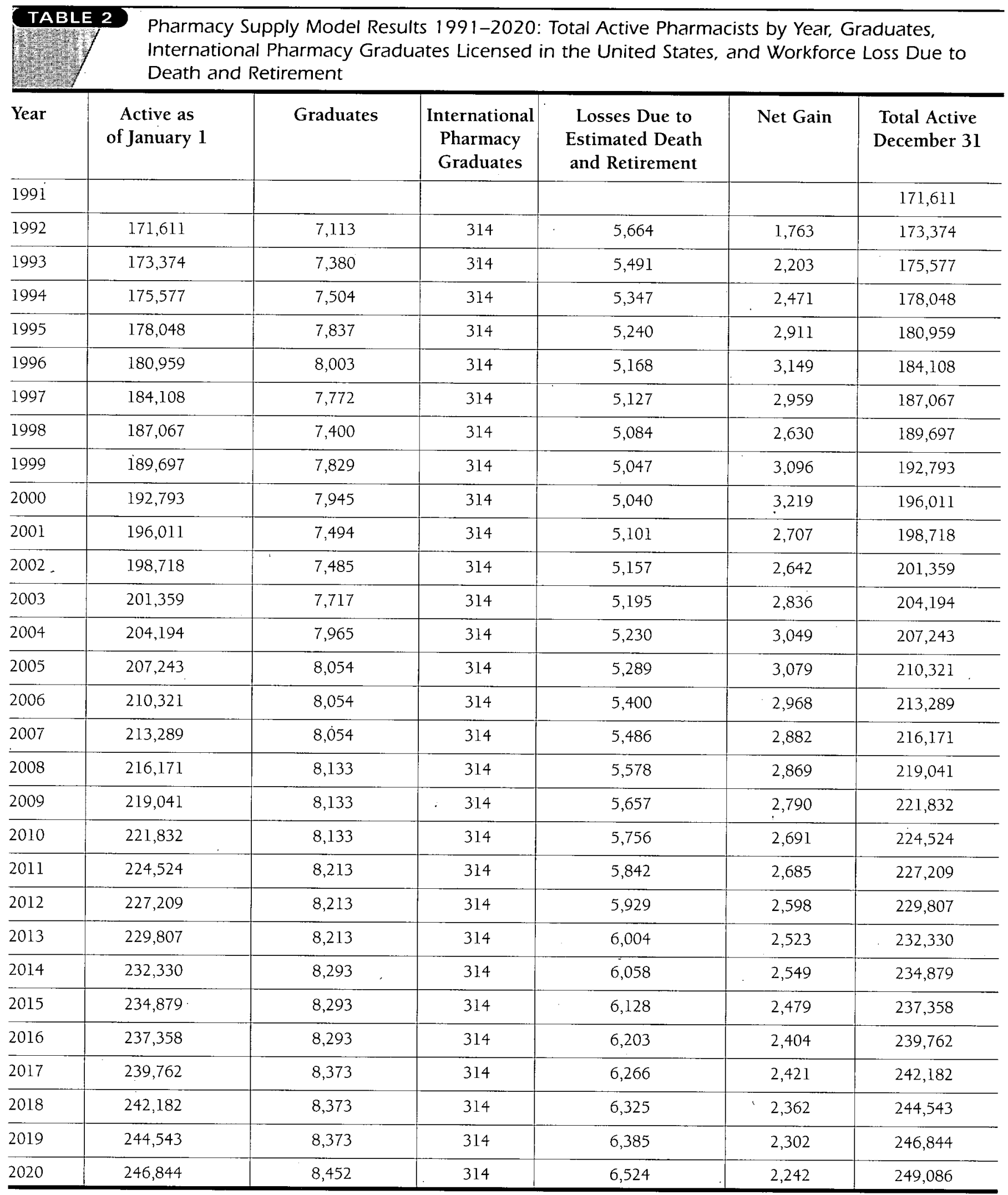




\begin{tabular}{ll}
\hline TABLE 3 & $\begin{array}{l}\text { Ratio of Active Pharmacists to } \\
100,000 \text { Population: } 1995-2020\end{array}$ \\
\hline Year & Pharmacists per 100,000 Population $^{\text {a }}$ \\
\hline 1995 & 68.9 \\
\hline 2000 & 71.2 \\
\hline 2005 & 73.1 \\
\hline 2010 & 74.9 \\
\hline 2015 & 76.0 \\
\hline 2020 & 76.7 \\
\hline
\end{tabular}

${ }^{a} U . S$. population data from the U.S. Census Bureau.

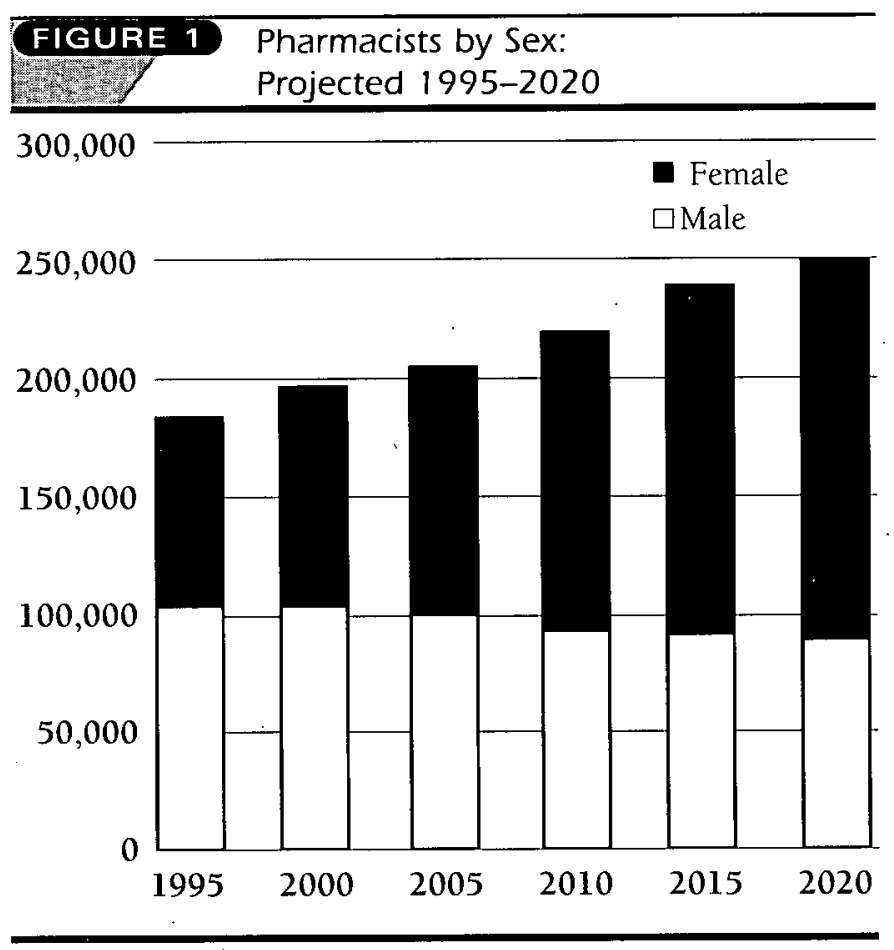

Table 3, above, describes the ratio of pharmacists per 100,000 population from 1995 through 2020. The supply is expected to expand at a slightly higher rate than the general population. Currently, in 2000, we estimate 71.2 pharmacists per 100,000 population. The ratio is expected to rise to 74.9 per 100,000 people in 2010 , and reach 76.7 per 100,000 in 2020. The alternative series projects the pharmacist-to-population ratio to range from 74.0 (low series) to 75.6 (high series) per 100,000 in 2010, and 74.5 (low series) to 78.1 (high series) in 2020 . These results indicate that even with no new schools or no expansion of existing schools during the projection peri- od, the supply growth rate will still outpace the population growth rate, which is about $1.01 \%$ annually.

Figure 1 , left, shows the distribution of the workforce by sex from 1991-2020. In 1991 approximately 32\% of pharmacists were women. Since then, increases in first-year enrollments of women in pharmacy schools have resulted in substantial growth in the numbers of women pharmacists in all positions. Also contributing to the increasingly female workforce is the projection that pharmacists leaving the workforce will be predominantly men. Currently women are estimated to represent $46 \%$ of the pharmacist supply. By 2003 about $50 \%$ of active pharmacists are expected to be women. By 2020, men are expected to constitute only $36 \%$ of the total supply.

Figure 2, page 479, shows the estimated age distribution of active pharmacists in 2000 by sex. The curve is not smooth because we used five-year separation rates instead of one-year rates. The upturn at age 75 is an artifact reflecting pharmacists remaining in the model at age 75 , the last cohort. Because of this distortion, the values at age 75 were not used in calculating the mean or median ages. The mean and median ages for mer pharmacists were both 46 years, for women pharmacists they were 38 and 35 years, and for all pharmacists they were 42 anc 40 years, respectively.

Figure 3, page 480, describes a combination of historica and projected estimates of total graduates from 1980 to 2020 Percentages of graduates receiving the B.S. degree decreasec from $94 \%$ (1980) to $86.4 \%$ (1990) to $64.4 \%$ (1998). Graduate numbers, which decreased more than $20 \%$ in the 1980 s rebounded in the 1990s, rising to a high of 8,003 in 1996 anc decreasing again through 1998 . The decreased number of grad. uates during the 1980s is reflected in the base counts for oul model, and its influence continues to be felt today in a lower supply than might otherwise have occurred.

Figure 4, page 481, gives estimates of graduates from 199] through 2006. After 2003 the alternative series diverges basec on differing assumptions about new schools. U.S. graduates art projected to number 7,945 in $2000,8,133$ in 2010 , and 8,45 i in 2020 in the basic series. Estimated graduates in the low serie: are 7,943 in both 2010 and 2020 . Estimates for the high serie! are 8,293 in 2010 and 8,692 in 2020. The low series shows 50s fewer graduates in 2020 than the basic series, whereas the high series has 240 more graduates than the basic series. We did no estimate the percentage of the overall workforce holding each degree for the projection years.

\section{Discussion}

As a test of the model's validity in estimating pharmacist num bers, we investigated other estimates of pharmacist number: and pharmacy positions. We compared the 1997 to 1999 esti mates of total active pharmacists in our model with thos reported by BLS and the Census Bureau, recognizing that gen erally Census Bureau data are based on counts of people whil 


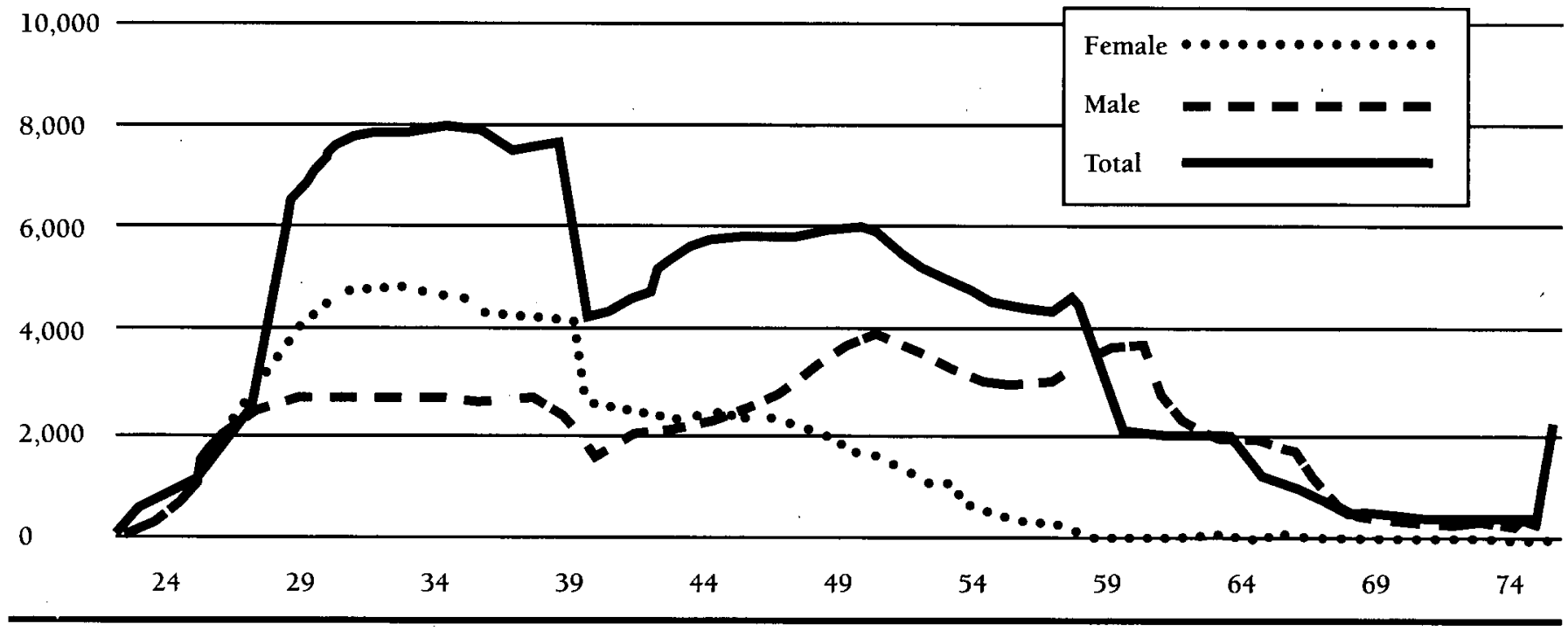

BLS data are based on positions. The values in the BHPr model for these three years were $187,067,189,697$, and 192,793 active pharmacists, respectively. Current Population Survey (CPS) data collected by the Census Bureau reported 200,000 pharmacists in 1997 with 195,000 counted as wage and salary workers (employees) and 5,000 counted as self-employed workers (BLS, unpublished data, 2000). For 1998 the Census Bureau reported 180,000 pharmacists with 173,000 counted as wage and salary workers and 6,000 as self-employed workers. The corresponding figure for 1999 was 216,000 pharmacists with 204,000 reported as employees and 11,000 as selfemployed workers (BLS, unpublished data, 2000). The wide variation in CPS data for the three years was a result of the relatively small number of pharmacists sampled, with values falling above and below the BHPr estimates.

A second comparison was made with data from the revised BLS 1998 National Occupational Employment and Wage Estimates. This source reported the number of pharmacists as 174,540 for 1997 and 178,110 for 1998 (BLS, unpublished data, 2000). Data for 1999 were not available. These data were collected from employers and did not include self-employed pharmacists; when self-employed pharmacist estimates from CPS data are added, these totals approximate those in our model. Corroborating data also came from the BLS National Industry-Occupation Employment Matrix from 1998, which reported a total of 185,324 pharmacists according to their place of employment (BLS, unpublished, 2000; corroborated by a BLS report of 185,000 pharmacists in 1998) ${ }^{14}$ Finally, in a separate report, BLS Occupational Employment Statistics reported a total of 177,350 employed pharmacists in 1998 (BLS, unpublished data, 2000). All of the reports, after adjustment to include self- employed pharmacists, suggested that the totals calculated in the BHPr Pharmacist Supply Model were reasonably representative of the U.S. active pharmacy workforce.

Validation of the total pharmacist numbers through 1998 allowed us to draw conclusions about the validity of other aspects of the model. In creating the model, we made assumptions about numbers of U.S. graduates and IPGs, numbers of schools, and an appropriate set of separation rates. For the years 1991 through 1998, detailed data about graduates and schools were available, as were limited data about IPGs. With these values known, the predictive capacity of the model through 1998 became a measure of the validity of the separation rates we selected, and, to a lesser extent, estimates of IPGs. The agreement between the model totals and counts from other sources increased our confidence about the choice of separation rates and IPG estimates.

A slowly increasing pharmacist-to-population ratio was estimated for 1991-2020, yet we know that the 1990s were marked by fluctuations in the supply-to-demand balance in the marketplace. This finding suggests that this single measure is insufficient for judging the adequacy of the pharmacist supply. An explanation of events such as the current shortage of pharmacists requires exploration of multiple factors extending beyond supply issues and including, for example, the numbers of elderly Americans, the proliferation of prescription drug benefits, the increased numbers of prescriptions, and the changing roles of pharmacists. Although that task is beyond the scope of this article, for that larger consideration, the results from our study will be helpful in addressing supply-related issues.

We compared the model's age distribution in 2000 with the age distribution described by the 1991 PMP census data. ${ }^{11}$ The 


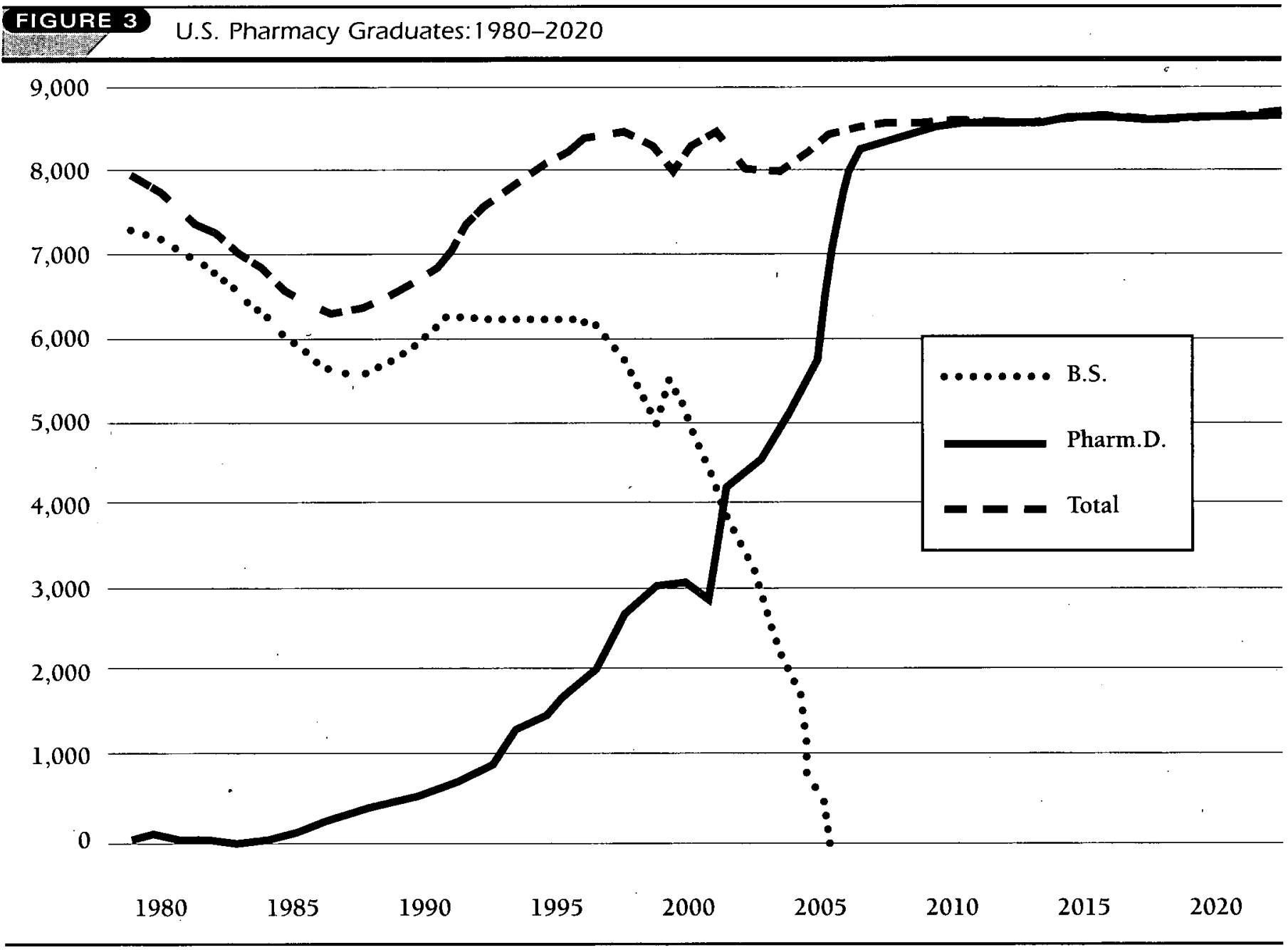

mean age for the PMP census was 44.4 years, with the mean for women being 37.5 years and for men 47.6. While the latter two means were very similar, the change in the sex ratio since 1991 decreased the model's mean age by more than two years. Thus, the overall workforce has become slightly younger in the last decade. We also noted that the model's mean age of 42 years in 2000 was similar across several more recent studies. For example, a 1995 analysis of 1,637 pharmacist surveys found a mean age of 43 years, and a 2000 analysis of 2,092 surveys found a mean age of 42.6 years for active pharmacists working full-time and 48.6 years for part-time pharmacists. ${ }^{7,15}$

The introduction of IPGs made the model more representative of the pharmacy workforce. Nevertheless, with so few data available and such uncertainty about the future for IPG licensure in the United States, it was difficult to justify predicting either increases or decreases in future IPG workforce entrants. Although we addressed this dilemma by using constants for the three series, this could be seen as a temporary measure. As the questions currently surrounding the future of IPGs in the U.S. workforce are answered, the model should be adjusted to reflect the extent of IPG licensure. The ability to make adjustments easily is a distinct advantage of the model.

Predicting graduates in the model was highly dependent on estimating the number and size of pharmacy schools in the future. The telephone inquiry allowed us to estimate the nearfuture impact of changes such as the movement to the universal entry-level doctor of pharmacy degree. For the longer term, the continuing declines in the applicant pools and the recent surge in new schools present another dilemma in terms of opposing trends. Our assumption of adding one new school every three years in the basic series was a conservative choice, given recent history, and may therefore underestimate supply. The possible underestimation is balanced by assuming entering classes of 100 students in new schools, although several recently opened schools have offered only $75-80$ seats. As with IPGs, should future developments render the assumptions about new schools invalid, the model will need to be adjusted.

Whatever the number of new graduates, the fact that all new 


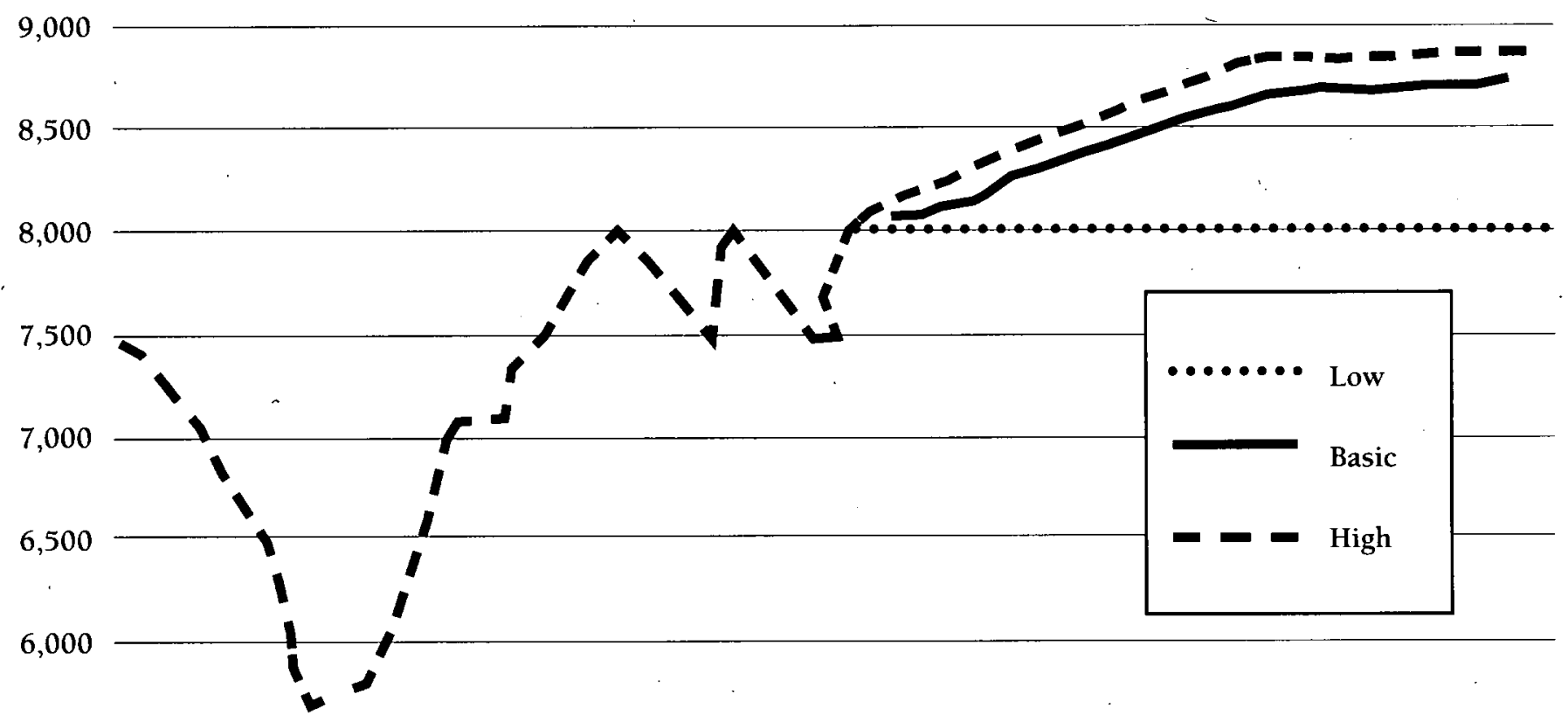

\section{5,500}

5,000

\section{0}

1985

1990

1995

2000

2005

2010

2015

2020

Note: "Low" assumes no schools of pharmacy added after 2000. "Basic" assumes three schools added between 2000 and 2010 and three more schools between 2010 and 2020. "High" assumes one new school added every other year throughout the projection period.

graduates will hold the doctor of pharmacy degree after 2003 is likely to have an effect on the workforce as pharmacy faces the challenges of new roles in health care. For example, pharmacists are contributing to public health initiatives such as immunization and smoking cessation programs, working in the managed care environment in disease-state management programs and as pharmacy benefit planners and managers, as well as expanding responsibility for the direct care of patients in clinic settings. ${ }^{16}$ With national implementation of the Pharm.D. requirement, new pharmacists entering the workforce will have completed more advanced college coursework before entering the professional program and will bring new knowledge and skills to the workplace. For many new roles, the additional maturity and preparation of future graduates will influence the image and utility of the pharmacist workforce. On a more mundane note, the end of the Pharm.D. transition will mark a period of greater certainty about graduate numbers.

The model shows a workforce consisting increasingly of women during the early 21 st century. It is important to remember that the model represents a count of active pharmacists and does not reflect the level of participation in the workforce. Many studies have shown that more women pharmacists work less than full-time than men pharmacists., ${ }^{3,4,14}$ Therefore, the head counts produced by our model almost certainly overestimate the full-time equivalent (FTE) size of the workforce. A calculation of the difference is beyond the scope of this article; however, a better understanding of the relationship between the model's "head count" estimates and the FTE count of pharmacists is an important research endeavor that should have high priority.

\section{Limitations}

The BHPr Pharmacist Supply Model is being revised to convert head counts to FTE measures, but its current inability to do so is a limitation. Other limitations related to our lack of knowledge about IPG trends and new schools have already been noted. Another notable gap in the data produced by the model is the lack of a geographic component. Most of the pharmacy manpower problems that have developed over the past 15 years have had a regional character. The data provided by the model 
do not improve our understanding of the national distribution of pharmacists now or in the future. The model's supply projections do not presently differentiate patient care and non-patient care components of supply, although we plan to add this feature. Finally, the BLS 1988 separation rates, although the best predictor among the rate sets studied, showed higher-than-expected diminution of the workforce after age 40 . For example, at age 40 , the total separation rate for both men and women is 0.0164 for the BLS rates versus 0.0016 for physician separation rates. Since the largest segment of the pharmacy workforce is older than 40 years, the model may underestimate the pharmacist workforce size.

\section{Conclusion}

The BHPr Pharmacist Supply Model provides three series of estimates of the total number of active pharmacists to the year 2020 by age and sex. It also estimates graduates by sex and degree. It includes annual estimates of IPGs and counts of pharmacists leaving the workforce by reason of death or retirement. The totals generated compared well with counts from other sources, increasing confidence in the model as a predictive tool. The model describes a workforce composed increasingly of women and holders of the doctor of pharmacy degree.

The perspective offered by the model gives health care policymakers and health care workforce researchers an important tool for estimating numbers of pharmacists and their demographic makeup in the future. Although limitations exist, they merely suggest where efforts are needed in research and data collection to improve the model's predictive capabilities. Amid a host of speculations about the future of pharmacy in the new century, this model will serve as a useful tool for providing accurate information on the supply of active pharmacists. It should be recognized as an important step in expanding knowledge about the pharmacy workforce through modeling. It also supports pharmacy's recent commitment to collectively look at issues that affect supply and demand. The utility of the model lies in its ability to move forward through time using known available data elements. More accurate data, such as separation rates that are specific to pharmacists or better estimates of num- bers of U.S. graduates, will improve the model's predictive capabilities. But even in the absence of such data, the model serves a useful purpose.

\section{References}

1. Beavers N. Feeling the weight: RPh shortages reported across nation as prescription load gets ready to reach four billion units. Drug Topics 2000;144(1): 38-41,47-48.

\section{65 Federal Register 1.4288-89 (2000)}

3. Knapp KK et al. Work patterns of male and female pharmacists: a longitudinal analysis 1960-1989. Eval and Health Prof 1992;15: 231-49.

4. Schondelmeyer SW et al. Final report of the national pharmacists' compensation survey: 1990-91. Washington, DC: American Pharmaceutical Association; 1992.

5. Mason HL, D'Elia RP. The supply of pharmacist personnel over time. J Res Pharm Econ 1994; 5(4): 125-44

6. Knapp KK. Pharmacy manpower: implications for pharmaceutical care and health care reform. Am J Hosp Pharm 1994; 51: 1212-20.

7. Quiñones AC, Mason HL. Characterizing pharmacy part-time practice. J Am Pharm Assoc 2000; 40: 17-25

8. Shih YT. Trends in full-time pharmacists' labor market characteristics. J Am Pharm Assoc 2000; 40: 26-35.

9. Mott DA. Pharmacist job turnover, length of service, and reasons for leaving, 1983-1997. Am J Health-Syst Pharm 2000; 57: 975-82.

10. Bond CA, Raehl CL. Changes in pharmacy, nursing, and total personnel staffing in U.S. hospitals, 1989-1998. Am J Health-Syst Pharm 2000; 57: 970-04.

11. Vector Research, Inc. Pharmacy Manpower Project: State and National Survey Reports. Ann Arbor, MI: Vector Research Inc; 1994.

12. Knapp K,'Lipson D, Simpson K. California pharmacy manpower: present and future, part I. Calif Pharm 1986; 34; 37-44, 54.

13. Knapp KK, Paavola F, Manasse H Jr. Models for the supply of pharmacists. Eval Health Prof 1990; 3: 343-63.

14. Bureau of Labor Statistics. Occupational Outlook Handbook. Available at: http://stats.bls.gov/oco/oco5079.htm. Accessed September 29, 2000.

15. Pedersen CA et al. National pharmacist workforce survey: 2000. Available at: www.aacp.org/Resources/Profiles_Reports/manpower.html. Accessed September 29, 2000.

16. Maddux MS et al. A vision of pharmacy's future roles, responsibilities, and manpower needs in the United States. Pharmacotherapy 2000; 20: 991-1020 